\title{
Effects of Visual Information on Joint Angular Velocity of Trunk and Lower Extremities in Sitting and Squat Motion
}

\author{
Kyoung hee $\mathrm{Bu}^{1}$, Tae young $\mathrm{Oh}^{2}$ \\ ${ }^{1}$ Graduate School, Silla University; ${ }^{2}$ Department of Physical Therapy, College of Medical Life Science, Silla University, Busan, Korea
}

Purpose: The purpose of this study is to determine the effects of visual information on movement time and each angular velocity of trunk and lower extremity joints while healthy adults are in sitting and squat motion.

Methods: Participants consisted of 20 healthy male and female adults; movement time and each angular velocity of trunk, pelvis, hip, knee and ankle of sitting and squat motion according to common vision, visual task and visual block were analyzed using a three dimensional motion analysis system.

Results: Each angular velocity of the trunk, pelvis, hip, knee and ankle in phase 2 of the sitting showed significant difference according to the types of visual information $(p<0.05)$. Movement time and each angular velocity of pelvis and hip in phase 2 of squat motion showed significant difference according to the types of visual information $(p<0.05)$. According to the common vision, each angular velocity of knee and ankle in phase 1 was significantly fast in sitting $(p<0.05)$. According to the common vision, each angular velocity of trunk, pelvis, hip, knee, and ankle in phase 2 was significantly fast in sitting $(p<0.05)$.

Conclusion: Visual information affects the angular velocity of the motion in a simple action such as sitting, and that in more complicated squat motion affects both the angular velocity and the movement time. In addition, according to the common vision, visual task and visual block, as angular velocities of all joints were faster in sitting than squat motion.

Keywords: Vision Information. Sitting, Squat Motion, Kinematic Analysis

\section{서 론}

선 자세에서 앉기 동작은 일상생활에서 과제해결을 위하여 가장 많 이 사용되는 일상생활 동작 중 하나이며, ${ }^{1}$ 의자에 앉거나 무릎을 꼻고 바닥에 앉는 것 같은 스쿼트 동작 또한 일상생활에서 과제수행을 위 하여 사용된다. ${ }^{2} \mathrm{Kerr}$ 등 ${ }^{3}$ 은 선 자세에서 앉기 동작을 체간의 전방굴 곡, 체간의 하향이동, 슬관절의 굴곡, 체간의 후방이동(안정화)으로 분 류하였으며 각각의 요소로는 전방기울기, 수직선상의 흔들림, 슬관절 의 굴곡, 원상태 회복이라고 하였다. 스쿼트 동작은 시상면에서 허리 를 바로 세우고 무릎이 발 끝 앞으로 나가지 않게 하고 내측으로 쏠리 지 않게 하는 자세를 유지하여 슬관절을 굴곡하는 자세이며, ${ }^{4}$ 허리를 바로 세운 상태에서 슬관절 중립상태로 신체가 하향하는 동작이다. ${ }^{5}$

Hase 등6은 앉기의 시작과 함께 비복근과 척추기립근의 활성이 나 타나며 체간이 뒤로 이동하는 후방 모멘텀의 발생으로 신체의 압력 중심은 전방으로 이동한다고 하였다. 앉기의 진행으로 고관절과 슬
관절의 굴곡이 나타나며 슬괵근과 척추기립근의 활성을 통해 체간 이 뒤로 향하는 것을 조절하면서 고관절 굴곡을 통해 신체가 내려가 는 속도를 조절한다고 하였다.

스쿼트 동작은 전경골근의 활성과 동시에 신체의 압력중심이 후 방으로 이동되며, 하지의 각 관절들의 굴곡을 통해 스쿼트 동작이 진 행되면서 척추기립근과 슬괵근들의 동시수축으로 체간과 하지가 내 려가는 동안 신체를 스쿼트 자세로 유지시키게 된다.

이러한 자세조절은 기계적요인과 신경학적요인의 영향을 받는다. 신경학적 요인은 반응에 대한 운동출력기전을 포함하며, 감각처리과 정에는 시각계, 전정계, 고유수용계를 포함한다. 자세조절에 영항을 미치는 중요한 요인에는 지지 면의 크기와 형태, 관절의 가동 범위, 근 력 및 체성 감각기능의 발달 정도 등이 있으며, 이와 함께 다양한 감 각운동 시스템의 상호작용을 통해 중력 작용의 여부, 지지 면의 상태, 시각정보 제공의 여부 및 외부 환경에 대해 능동적으로 신체의 안정 성과 긴장도를 조절할 수 있는 능력이 고려되어야 한다. 
시각 시스템은 눈을 감는 것과 같이 시각을 차단하거나 시각의 상 태를 제한함으로써 자세동요(postural sway)가 증가되는 것과 같이 자 세균형조절에 우위를 차지한다. ${ }^{9}$ Shumway-Cook과 Woollacott 는 시 각은 균형과 자세를 유지하는 데 중요한 역할을 하며, 시각이 차단되 거나 결손 시에는 전정감각, 고유수용감각, 촉각 등의 감각 정보를 통 하여 자세를 조절하거나 균형을 유지하게 된다고 하였으며, 자세조절 과 함께 이루어지는 인지를 필요로 하는 과제의 수행은 자세조절을 위한 운동조절 능력을 방해하거나 새로이 자세조절을 하는 데 영향 을 미친다. ${ }^{10,11}$

Dubost 등 12 은 앉기 동작에서 체간의 각도 변화를 연구한 결과에 서 연령이 증가 할수록 체간의 전방굴곡이 감소하며, 동작 수행 동안 체간의 움직임의 양 또한 줄어들어 결국 전방에서 평형을 유지하는 데 어려움이 생긴다고 하였다. Donnelly 등 13 은 스쿼트 동작에서 상방, 전방, 하방으로 한 시선의 위치에 따라 달라지는 운동학적 변인을 연 구한 결과에서 상방을 보고한 스쿼트 동작보다 하방을 보고 수행한 스쿼트 동작에서 체간과 고관절의 굴곡이 유의하게 크게 나타났다 고 하였다.

Flanagan 등 ${ }^{14}$ 은 일반적인 스쿼트(normal squat)동작과 의자 스쿼트 (chair squat)동작의 운동학적, 운동역학적 비교 연구에서 의자 스쿼 트 동작이 일반적인 스쿼트 동작보다 최대의 고관절 굴곡각도, 최대 모멘트, 힘, 일률을 보였으며 이는 의자 스쿼트 동작은 고관절 신전근 의 큰 활동이 필요하게 되며, 일반적인 스쿼트 동작에서는 슬관절의 신전과 족관절 저측 굴곡의 능력이 필요하게 된다고 하였다.

따라서 본 연구의 목적은 정상성인을 대상으로 시각정보에 따라 앉기와 스쿼트 동작의 수행시간과 체간 및 하지 관절 각속도에 미치 는 영향을 3 차원 동작 분석 시스템을 통해 알아보고자 하는 것이다.

\section{연구 방법}

\section{1. 연구대상}

본 연구의 대상은 부산시내에 거주하는 20,30 대 성인 남성 12 명과 여 성 8 명으로 총 20 명이 연구에 참여하였다. 연구 대상은 사지의 선천적 인 기형이나 심각한 내.외과적 혹은 신경학적인 질환이 없는 자로 실 험에 대한 설명을 듣고 실험 참가에 서면 동의하였다. 연구 대상은 남 자에서 평균 $27.58 \pm 2.12$ 세, $72.17 \pm 2.64 \mathrm{~kg}, 174.50 \pm 1.49 \mathrm{~cm}$ 와 여자에서 평균 $22.38 \pm 1.37$ 세, $50.63 \pm 1.66 \mathrm{~kg}, 161.63 \pm 1.69 \mathrm{~cm}$ 이었다.

\section{2. 연구 도구}

1) 3차원 동작 분석 시스템

(1) 공간좌표화

본 연구의 공간 좌표화를 위하여 전역 좌표계는 연구 대상자를 정면
에서 바라본 관점에서 우측 후방에 원점을 두고, 전방을 $\mathrm{Y}$ 축, 수직방 향을 Z축으로 각각 설정하며, X축은 두 벡터의 외적으로 설정하였다.

본 연구의 3 차원 공간 좌표 설정을 위해 마커가 붙어있는 L자형 Orientation frame (Qualisys Inc, Sweden)을 전역 좌표계의 원점에 설치 후 마커가 붙어있는 T자형 Calibration wand (Qualisys Inc, Sweden)를 30 초간 실험 공간을 모두 포함하도록 움직여 분석범위를 설정하였다. T자형 기준척도를 골고루 움직여서 획득한 공간상의 위치 정보를 NLT (Non-linear transformation method) 방법을 이용하여 산출하였다.

\section{(2) 촬영 카메라}

연구 대상자의 앉기와 스쿼트 동작을 촬영하기 위해 동작분석용 카 메라(Oqus seris 5, Qualisys Inc, Sweden) 5대를 사용하였다. 이 카메라 는 최대 10,000 frames/sec까지 촬영할 수 있으며, 촬영과 동시에 실시 간으로 3 차원 위치좌표를 얻을 수 있는 적외선 카메라(infrared camera)이다. 본 연구에서의 샘플링(sampling rate)은 80 frames/sec로 설정 하였다.

\section{(3) 측정 프로그램}

Qualisys Track Manager 프로그램(Qualisys Inc, Sweden)을 사용하여 연구 대상자의 신체 각 지점에 부착된 반사마커의 3 차원 공간 좌표 값을 추출하였으며, Visual 3D (C-Motion Inc, USA) 프로그램을 이용 하여 변인을 분석하였다.

\section{(4) 표식자 부착 부위}

본 연구는 Visual 3D의 CODA모델에 맞도록 신체의 양측에 마커 (marker)와 클러스터(cluster)를 부착하여 총 36 개의 표식자를 사용하 였다.

\section{(5) 정적 자세 촬영}

본 연구에서 각 관절의 중심점의 위치를 찾기 위하여 실험 측정 전에 정지된 상태에서 촬영된 영상(static trial)을 이용하였으며, 대상자에 게 부착된 해부학적 마커 정보를 이용하여 각 관절과 발, 하퇴, 대퇴, 골반, 상체, 머리의 각 분절을 모델링 하였다

\section{(6) 동작구간의 설정}

운동학적 요인인 관절각속도를 구하기 위하여 앉기와 스쿼트 동작 의 구간을 하퇴의 수직선상에서 대퇴의 움직임을 기준으로 하는 슬 관절 굴곡 각도를 이용하여 구간 1과2로 구분하였다.

(1) 구간 1 (Phase, P1): Knee flexion $0^{\circ}-45^{\circ}$

(2) 구간 2 (Phase, P2): Knee flexion $45^{\circ}-90^{\circ}$ 


\section{2) 시각 정보의 변화를 위한 도구}

(1) 손전등

연구 대상자에게 시각과제를 제공하기 위하여 손전등(prokan X2000-K13, Prokan Inc, China)을 사용하였다. 조명은 연구 대상자의 후면에서 전방으로 제공하였으며, 조명을 조정할 연구보조자 1 명의 도움을 받았다. 조명과의 거리는 연구 대상자의 $2 \mathrm{~m}$ 전방으로 시선에 맞게 제공하였고, 촬영장을 암전상태로 하여 조명에 집중할 수 있는 환경을 제공하였다.

\section{(2) 안대}

연구 대상자에게 시각차단을 위하여 안대를 사용하였다. 안대는 뒤 의 조절끈이 부착되어 개인의 얼굴둘레에 맞게 빈틈없이 눈을 가릴 수 있게하였다.

\section{3) 실험절차}

(1) 앉기와 스쿼트 동작의 시작 자세

연구 대상자를 선 자세에서 양 팔을 교차시켜 가슴에 모은 상태로 양 발은 $15 \mathrm{~cm}$ 간격으로 벌리고 시선은 전방을 향하게 하였으며, 팔걸이 와 등받이가 없는 $40 \mathrm{~cm}$ 높이의 의자를 뒤꿈치와 $15 \mathrm{~cm}$ 거리에 위치 하도록 하였다

\section{(2) 앉기와 스쿼트 동작의 수행}

일반 앉기(Sitting)와 스쿼트 동작(Squat motion)의 수행은 연구 대상 자에게 평가자의 “앉으세요”라는 구두지시에 따라 후면의 팔걸이와 등받이가 없는 의자에 앉기와 스쿼트 동작을 수행하도록 하였으며, 시각과제(Visual task) 앉기와 스쿼트 동작은 연구 대상자에게 암전상 태에서 전방에 위치한 조명에 시선을 집중시킨 상태로 평가자의 "조 명이 꺼지면 멈추세요”라는 과제와 “앉으세요”라는 구두지시에 따라 후면의 팔걸이와 등받이가 없는 의자에 시각과제를 통한 앉기와 스 쿼트 동작을 수행하도록 하였다.

또한 시각차단(Visual block) 앉기와 스쿼트 동작의 수행은 연구 대 상자에게 안대를 착용시킨 상태로 평가자의 "앉으세요"라는 구두지 시에 따라 후면의 팔걸이와 등받이가 없는 의자에 시각차단 앉기와 스쿼트 동작을 수행하도록 하였다.

\section{3. 자료 처리}

6가지 서로 다른 앉기와 스쿼트 동작을 수행하기 위해 연구 대상자 는 연구일정에 따라 촬영장에 1 명씩 입장하여 서로 마주치지 않게 하 였으며, 제비뽑기를 통해 앉기와 스쿼트 동작을 구분한 후 일반시각 앉기(common vision sitting)와 시각과제 앉기(visual task sitting), 시각 차단 앉기(visual block sitting), 일반시각 스쿼트 동작(common vision squat motion), 시각과제 스쿼트 동작(visual task squat motion), 시각차 단 스쿼트 동작(visual block squat motion) 순으로 수행하도록 하였다. 이때 각 과제의 학습을 방지하기 위하여 앉기와 스쿼트 동작 중간에 휴식시간 5 분을 제공하였다. 각각의 동작은 사전 연습 없이 총 3 번씩 이루어 졌으며 마커의 위치가 가장 선명하게 촬영된 한 가지의 결과 만을 가지고 연구 자료로 사용하였다.

\section{4. 분석 방법}

시각정보 변화에 따라 앉기와 스쿼트 동작에서 수행시간과 체간 및 하지 관절 각속도 분석을 위하여 반복측정 분산분석(repeated ANO$\mathrm{VA}$ )을 사용하였으며, 각각 개체 내 대비검정을 이용하여 사후검정 (post hoc)을 하였다. 시각정보 변화에 따른 앉기와 스쿼트 동작을 비 교하기 위하여 대응표본 t-검정(paired t-test)을 사용하였다.

자료분석은 SPSS Win (ver. 22.0) 프로그램을 사용하였으며, 모든 통 계에 대한 유의 수준은 $\alpha=.05$ 로 하였다.

\section{결 과}

\section{1. 시각정보에 따른 앉기와 스쿼트 동작의 수행시간 분석}

시각정보에 따라 앉기의 수행시간은 유의한 차이가 없었으며, 스쿼 트 동작의 수행시간은 4.22 초, 4.28 초, 3.65 초로 유의한 차이가 나타났 다 $(\mathrm{p}<0.05)$.

\section{2. 앉기와 스쿼트 동작 시 시각 정보에 따른 체간 및 하지 관절 각속도 분석}

1) 시각 정보에 따른 체간 각속도 분석

앉기에서 체간 각속도는 시각정보에 따라 구간 1 에서는 유의한 차이 가 없었으며 구간 2에서 유의한 차이가 있었다 $(\mathrm{p}<0.05)$ (Table 1). 앉기 의 구간 2에서 일반시각 상태가 시각과제와 시각차단보다 유의하게 체간 각속도가 빠르게 나타났다 $(\mathrm{p}<0.05)$.

스쿼트 동작에서 체간 각속도는 시각정보에 따라 구간 1,2 모두에 서 유의한 차이가 나타나지 않았다(Table 1).

\section{2) 시각 정보에 따른 골반 각속도 분석}

앉기에서 골반 각속도는 시각정보에 따라 구간 1 에서는 유의한 차이 가 없었으며, 구간 2에서 유의한 차이가 있었다 $(\mathrm{p}<0.05)$. 앉기의 구간 2에서 일반시각 상태가 시각과제와 시각차단보다 유의하게 골반 각 속도가 빠르게 나타났다 $(\mathrm{p}<0.05)$.

스쿼트 동작에서 골반 각속도는 시각정보에 따라 구간 1 에서는 유 의한 차이가 없었으며, 구간 2에서 유의한 차이가 있었다 $(\mathrm{p}<0.05)$. 스 쿼트 동작의 구간 2에서 시각과제가 일반시각과 시각차단보다 유의 
Table 1. Difference of angular velocity of trunk among each visual information in sitting and squat motion (Unit: $\% / s$ )

\begin{tabular}{|c|c|c|c|c|c|c|}
\hline & Phase & $\begin{array}{c}\text { Visual } \\
\text { information }\end{array}$ & $\begin{array}{l}\text { Angular } \\
\text { velocity }\end{array}$ & $\mathrm{F}$ & $\mathrm{p}$ & $\begin{array}{l}\text { post } \\
\text { hoc }\end{array}$ \\
\hline \multirow[t]{6}{*}{ Sitting } & 1 & $\mathrm{CV}^{\mathrm{A}}$ & $19.24 \pm 8.60^{*}$ & 2.312 & 0.128 & - \\
\hline & & $V T^{B}$ & $16.15 \pm 8.86$ & & & \\
\hline & & $V^{C}$ & $17.46 \pm 8.10$ & & & \\
\hline & 2 & $\mathrm{CV}^{\mathrm{A}}$ & $23.14 \pm 8.01$ & 9.396 & 0.002 & $A>B$ \\
\hline & & $V T^{B}$ & $15.87 \pm 5.52$ & & & $A>C$ \\
\hline & & $V^{C} C$ & $18.26 \pm 6.56$ & & & $B=C$ \\
\hline \multirow[t]{6}{*}{ Squat motion } & 1 & $\mathrm{CV}^{\mathrm{A}}$ & $16.60 \pm 9.74$ & 0.297 & 0.747 & - \\
\hline & & $V T^{B}$ & $15.67 \pm 6.18$ & & & \\
\hline & & $V^{C}{ }^{C}$ & $16.64 \pm 7.01$ & & & \\
\hline & 2 & $\mathrm{CV}^{\mathrm{A}}$ & $13.52 \pm 6.97$ & 1.447 & 0.261 & - \\
\hline & & $V T^{B}$ & $12.31 \pm 5.29$ & & & \\
\hline & & $V^{C}$ & $14.03 \pm 5.82$ & & & \\
\hline
\end{tabular}

$\mathrm{CV}$, common visual; VT, visual task; VB, visual block.

${ }^{*}$ Mean \pm SD.

Table 2. Difference of angular velocity of pelvis among each visual information in sitting and squat motion (Unit: $\% / s$ )

\begin{tabular}{|c|c|c|c|c|c|c|}
\hline & Phase & $\begin{array}{c}\text { Visual } \\
\text { information }\end{array}$ & $\begin{array}{l}\text { Angular } \\
\text { velocity }\end{array}$ & $\mathrm{F}$ & $\mathrm{p}$ & $\begin{array}{l}\text { post } \\
\text { hoc }\end{array}$ \\
\hline \multirow[t]{6}{*}{ Sitting } & \multirow[t]{3}{*}{1} & $\mathrm{CV}^{\mathrm{A}}$ & $11.87 \pm 6.95^{*}$ & \multirow[t]{3}{*}{1.646} & \multirow[t]{3}{*}{0.221} & \multirow[t]{3}{*}{-} \\
\hline & & $V T^{B}$ & $10.13 \pm 7.05$ & & & \\
\hline & & $V B^{C}$ & $11.06 \pm 6.21$ & & & \\
\hline & \multirow[t]{3}{*}{2} & $C V^{A}$ & $18.38 \pm 6.61$ & \multirow[t]{3}{*}{6.870} & \multirow[t]{3}{*}{0.006} & $A>B$ \\
\hline & & $V T^{B}$ & $12.82 \pm 6.16$ & & & $A>C$ \\
\hline & & $\mathrm{VB}^{\mathrm{C}}$ & $15.49 \pm 6.50$ & & & $B=C$ \\
\hline \multirow[t]{6}{*}{ Squat motion } & \multirow[t]{3}{*}{1} & $C V^{A}$ & $13.13 \pm 7.83$ & \multirow[t]{3}{*}{0.764} & \multirow[t]{3}{*}{0.480} & \multirow[t]{3}{*}{-} \\
\hline & & $V T^{B}$ & $12.22 \pm 6.42$ & & & \\
\hline & & $V^{C}$ & $13.52 \pm 5.86$ & & & \\
\hline & \multirow[t]{3}{*}{2} & $\mathrm{CV}^{\mathrm{A}}$ & $12.98 \pm 7.50$ & \multirow[t]{3}{*}{8.593} & \multirow[t]{3}{*}{0.002} & $A>B$ \\
\hline & & $V T^{B}$ & $8.25 \pm 4.66$ & & & $A=C$ \\
\hline & & $V B^{C}$ & $12.54 \pm 5.51$ & & & $B<C$ \\
\hline
\end{tabular}

$\mathrm{CV}$, common visual; VT, visual task; VB, visual block.

${ }^{*}$ Mean \pm SD.

하게 골반 각속도가 느리게 나타났다 $(\mathrm{p}<0.05)$ (Table 2).

\section{3) 시각 정보에 따른 고관절 각속도 분석}

앉기에서 고관절 각속도는 시각정보에 따라 구간 1 에서는 유의한 차 이가 없었으며, 구간 2 에서 유의한 차이가 있었다 $(\mathrm{p}<0.05)$. 앉기의 구 간 2에서 시각과제가 시각차단보다, 시각차단이 일반시각 상태보다 유의하게 고관절 각속도가 느리게 나타났다 $(\mathrm{p}<0.05)$.

스쿼트 동작에서 고관절 각속도는 시각정보에 따라 구간 1 에서는 유의한 차이가 없었으며, 구간 2에서 유의한 차이가 있었다 $(\mathrm{p}<0.05)$. 스쿼트 동작의 구간 2에서 시각차단이 일반시각 상태보다 유의하게 고관절 각속도가 빠르게 나타났다 $(\mathrm{p}<0.05)$ (Table 3).
Table 3. Difference of angular velocity of hip joint among each visual information in sitting and squat motion (Unit: $\%$ s)

\begin{tabular}{|c|c|c|c|c|c|c|}
\hline & Phase & $\begin{array}{c}\text { Visual } \\
\text { information }\end{array}$ & $\begin{array}{l}\text { Angular } \\
\text { velocity }\end{array}$ & $\mathrm{F}$ & $\mathrm{p}$ & $\begin{array}{l}\text { post } \\
\text { hoc }\end{array}$ \\
\hline \multirow[t]{6}{*}{ Sitting } & 1 & $\mathrm{CV}^{\mathrm{A}}$ & $42.14 \pm 15.73^{*}$ & 1.697 & 0.211 & - \\
\hline & & $V T^{B}$ & $36.87 \pm 15.77$ & & & \\
\hline & & $V^{C}{ }^{C}$ & $28.28 \pm 15.41$ & & & \\
\hline & 2 & $\mathrm{CV}^{\mathrm{A}}$ & $54.72 \pm 11.58$ & 29.582 & 0.000 & $A>C$ \\
\hline & & $V T^{B}$ & $37.85 \pm 9.86$ & & & $A>B$ \\
\hline & & $V B^{C}$ & $45.30 \pm 10.12$ & & & $B<C$ \\
\hline \multirow[t]{6}{*}{ Squat motion } & 1 & $C V^{A}$ & $36.06 \pm 18.47$ & 0.867 & 0.437 & - \\
\hline & & $V T^{\mathrm{B}}$ & $36.16 \pm 11.87$ & & & \\
\hline & & $V^{C}$ & $38.46 \pm 14.16$ & & & \\
\hline & 2 & $\mathrm{CV}^{\mathrm{A}}$ & $29.59 \pm 8.22$ & 5.985 & 0.010 & $A=B$ \\
\hline & & $V T^{B}$ & $30.78 \pm 11.24$ & & & $A<C$ \\
\hline & & $V^{C}{ }^{C}$ & $33.62 \pm 8.47$ & & & $B=C$ \\
\hline
\end{tabular}

$\mathrm{CV}$, common visual; $\mathrm{VT}$, visual task; $\mathrm{VB}$, visual block. ${ }^{*}$ Mean $\pm S D$.

Table 4. Difference of angular velocity of knee joint among each visual information in sitting and squat motion (Unit: $\% / s$ )

\begin{tabular}{|c|c|c|c|c|c|c|}
\hline & Phase & $\begin{array}{c}\text { Visual } \\
\text { information }\end{array}$ & $\begin{array}{l}\text { Angular } \\
\text { velocity }\end{array}$ & $\mathrm{F}$ & $\mathrm{p}$ & $\begin{array}{l}\text { post } \\
\text { hoc }\end{array}$ \\
\hline \multirow[t]{6}{*}{ Sitting } & 1 & $\mathrm{CV}^{\mathrm{A}}$ & $40.64 \pm 14.13^{*}$ & 0.610 & 0.554 & - \\
\hline & & $V T^{\mathrm{B}}$ & $37.66 \pm 13.27$ & & & \\
\hline & & $V B^{C}$ & $37.15 \pm 13.92$ & & & \\
\hline & 2 & $\mathrm{CV}^{\mathrm{A}}$ & $66.71 \pm 14.23$ & 10.149 & 0.001 & $A>B$ \\
\hline & & $V T^{B}$ & $49.93 \pm 16.27$ & & & $A=C$ \\
\hline & & $V^{C}{ }^{C}$ & $59.43 \pm 12.30$ & & & $B<C$ \\
\hline \multirow[t]{6}{*}{ Squat motion } & 1 & $\mathrm{CV}^{\mathrm{A}}$ & $29.03 \pm 15.24$ & 1.342 & 0.286 & - \\
\hline & & $V T^{B}$ & $31.98 \pm 8.69$ & & & \\
\hline & & $V^{C}{ }^{C}$ & $33.04 \pm 12.07$ & & & \\
\hline & 2 & $\mathrm{CV}^{\mathrm{A}}$ & $40.39 \pm 12.55$ & 2.033 & 0.160 & - \\
\hline & & $V T^{B}$ & $37.67 \pm 14.57$ & & & \\
\hline & & $V B^{C}$ & $43.06 \pm 10.49$ & & & \\
\hline
\end{tabular}

$\mathrm{CV}$, common visual; $\mathrm{VT}$, visual task; VB, visual block.

${ }^{*}$ Mean $\pm S D$.

4) 시각 정보에 따른 슬관절 각속도 분석

앉기에서 슬관절 각속도는 시각정보에 따라 구간 1 에서는 유의한 차 이가 없었으며, 구간 2 에서 유의한 차이가 있었다 $(\mathrm{p}<0.05)$. 앉기의 구 간 2에서 시각과제가 일반시각 상태와 시각차단보다 각각 유의하게 슬관절 각속도가 느리게 나타났다 $(\mathrm{p}<0.05)$.

스쿼트 동작에서 슬관절 각속도는 시각정보에 따라 구간 1 과 2 모 두에서 유의한 차이가 나타나지 않았다(Table 4).

\section{5) 시각 정보에 따른 족관절 각속도 분석}

앉기에서 족관절 각속도는 시각정보의 변화에 따라 구간 1 에서는 유 의한 차이가 없었으며, 구간 2에서 유의한 차이가 있었다 $(\mathrm{p}<0.05)$. 앉 
Table 5. Difference of angular velocity of ankle joint among each visual information in sitting and squat motion (Unit: $\%$ s)

\begin{tabular}{|c|c|c|c|c|c|c|}
\hline & Phase & $\begin{array}{c}\text { Visual } \\
\text { information }\end{array}$ & $\begin{array}{l}\text { Angular } \\
\text { velocity }\end{array}$ & $\mathrm{F}$ & $\mathrm{p}$ & $\begin{array}{l}\text { post } \\
\text { hoc }\end{array}$ \\
\hline \multirow[t]{6}{*}{ Sitting } & \multirow[t]{3}{*}{1} & $\mathrm{CV}^{\mathrm{A}}$ & $11.75 \pm 5.95^{*}$ & \multirow[t]{3}{*}{0.797} & \multirow[t]{3}{*}{0.466} & \multirow[t]{3}{*}{-} \\
\hline & & $V T^{\mathrm{B}}$ & $11.51 \pm 7.67$ & & & \\
\hline & & $V^{C}$ & $10.34 \pm 4.79$ & & & \\
\hline & \multirow[t]{3}{*}{2} & $C V^{A}$ & $15.84 \pm 5.03$ & \multirow[t]{3}{*}{1.848} & \multirow[t]{3}{*}{0.018} & $A>B$ \\
\hline & & $V T^{B}$ & $12.92 \pm 4.24$ & & & $A=C$ \\
\hline & & $V^{C}$ & $14.85 \pm 5.33$ & & & $B<C$ \\
\hline \multirow[t]{6}{*}{ Squat motion } & \multirow[t]{3}{*}{1} & $C V^{A}$ & $7.10 \pm 4.70$ & \multirow[t]{3}{*}{2.253} & \multirow[t]{3}{*}{0.134} & \multirow[t]{3}{*}{-} \\
\hline & & $V T^{B}$ & $8.86 \pm 3.47$ & & & \\
\hline & & $V^{C}$ & $8.81 \pm 4.29$ & & & \\
\hline & \multirow[t]{3}{*}{2} & $C V^{A}$ & $11.00 \pm 4.43$ & \multirow[t]{3}{*}{0.931} & \multirow[t]{3}{*}{0.412} & \multirow[t]{3}{*}{ - } \\
\hline & & $V T^{\mathrm{B}}$ & $9.85 \pm 4.38$ & & & \\
\hline & & $V^{C}$ & $10.48 \pm 4.32$ & & & \\
\hline
\end{tabular}

$\mathrm{CV}$, common visual; $\mathrm{VT}$, visual task; $\mathrm{VB}$, visual block.

${ }^{*}$ Mean \pm SD.

기의 구간 2에서 시각과제가 일반시각 상태와 시각차단보다 각각 유 의하게 족관절 각속도가 느리게 나타났다 $(\mathrm{p}<0.05)$.

스쿼트 동작에서 족관절 각속도는 시각정보의 변화에 따라 구간 1 과2 모두에서 유의한 차이가 나타나지 않았다(Table 5).

\section{고 찰}

본 연구는 부산시내에 거주하는 건강한 성인 남. 여 20명을 대상으로 시각정보의 변화가 앉기와 스쿼트 동작의 수행시간과 동작 구간 1 과 2에서 체간, 골반, 고관절, 슬관절, 족관절의 각속도에 미치는 영향에 대하여 3 차원 동작 분석 시스템을 통하여 연구하였다. 시각정보의 변 화는 일반 시각정보, 시각과제, 시각정보의 차단을 포함하였으며 시 각과제는 암전상태에서 조명을 통해 제공하였고 시각차단은 안대를 착용하여 앉기와스쿼트 동작을 수행하였다.

선 자세에서 앉기는 신체이동을 위해 일상생활에서 빈번히 사용 되는 동작이며, ${ }^{15}$ 중력과 함께 신체가 아래로 내려가는 동작이다.12 스 쿼트 동작은 가장 보편적으로 시행되는 하지의 닫힌 사슬 운동의 형 태로써 다관절을 사용한 저항운동이다. ${ }^{16}$ 앉기와 스쿼트 동작은 일 상생활과 과제수행을 위해 빈번하게 사용되는 동작이며, 체간과 하 지가 동시에 굴곡되는 유사한 순서로 이루어져 있다. ${ }^{6}$

Zijlstra 등근 힘판 위의 양 발에 힘의 이동에 정보를 토대로 신체 가 내려가기 시작하는 순간, 착석한 순간, 앉기가 종료된 순간으로 나 누어 정상인과 파킨슨병 환자의 서기와 앉기에 대하여 연구하였으 며, Alves 등18은 스쿼트 동작을 내려가는 구간인 원심성 구간과 올라 가는 구간인 구심성 구간으로 나누어 근전도 연구를 하였으며, 본 연 구는 앉기와 스쿼트 동작을 하퇴의 수직선상을 기준으로 하여 대퇴
의 후방 움직임인 슬관절 굴곡으로 구분하였으며, 구간 1은 슬관절 굴곡 0 도에서 45 도, 구간 2 는 슬관절 굴곡 45 도에서 90 도로 설정하여 3 차원 동작 분석 시스템을 이용하여 앉기와 스쿼트 동작의 수행시간 과 동작 구간 1 과 2에서 체간과 하지관절 각속도를 측정하였다.

시각 정보의 처리와 이용을 위해서는 일정한 시간이 요구되므로 주어진 동작 수행에서 시각정보의 이용가능성은 동작 수행시간과 밀접하게 관련된다. 이는 동작의 수행시간이 시각적 정보처리를 위 해 요구되는 최소한의 시간보다 짧을 경우, 시각정보는 동작 수행에 영향을 미칠 수 없게 된다고 하였으며 이러한 관점에서 최소한의 시 각정보처리 시간은 운동제어 상황에서 시각의 기여도를 결정하는 주 요인자들 중 하나이다. ${ }^{19}$

본 연구에서 시각정보의 변화에 따라 앉기의 수행시간은 유의한 차이가 없었으며 일반시각 스쿼트 동작과 시각과제 스쿼트 동작보다 시각차단 스쿼트 동작이 유의하게 빠르게 나타났다. 이는 본 연구에 서 시각정보의 변화가 앉기의 수행시간에는 영향을 미치지 않았으나 스쿼트 동작의 수행시간에 영향을 미친 점을 시각적 정보처리를 위 해 요구되는 최소한의 시간 때문이라 할 수 있으며, 일반시각 스쿼트 동작보다 시각차단 스쿼트 동작에서 시각정보의 차단으로 인해 자 세조절에 대한 시각 정보의 부족으로 동작수행시간이 빠르게 나타 난 것이라 사료된다.

Choi 등 ${ }^{20}$ 은 트레이드밀 보행과 트레이드밀 앞의 스크린을 통하여 주어지는 인지과제의 상관관계에 대한 연구결과에서 안정상태보다 스크린을 통해 과제를 수행하는 동안 응답시간이 증가하였으며, 이 에 대해 동작의 수행시간은 동작수행에 요구되는 정보 처리량과 복 잡성이 영향을 미친다고 하였다.

Potter과 Silverman ${ }^{21}$ 은 시각계, 전정계, 체성감각계는 균형조절을 위해서 유기적으로 작용을 하며, 만약 한 가지 감각계에 손상이 오면 다른 감각계가 작용하여 균형조절을 할 수 있다고 하였다. 이를 통해 신체는 자세조절을 위하여 운동경험과 감각정보를 유기적으로 사용 하며 한가지의 정보가 부족해지면 다른 정보로의 의존도를 조절함 으로써 자세조절을 유지한다고 할수 있다.

앉기에서 슬관절 신전근과 고관절 신전근의 원심성 수축을 토대 로 착석까지 동작이 유연하게 이루어지며, ${ }^{14}$ 스쿼트 동작에서 신체가 감속하며 내려가는 순간에는 내측광근과 외측광근을 포함하는 슬 관절 신전근의 강한 원심성 수축이 나타나며, 신체 굴곡에 대한 속도 를 조절하여 스쿼트 동작을 감속시킨다고 하였다.614,22 Hase 등은 신 체가 내려가는 속도는 고관절 굴곡을 통해 조절된다고 하였으며 앉 기에서 고관절 굴곡 속도가 스쿼트 동작보다 빠르게 나타난다고 하 였다.

Won 등23의 시각제공 유무에 따른 자세조절 연구결과에서 개안과 폐안을 통한 시각 정보의 차이가 체·평형 장치 위에서의 동적 균형조 
절을 위한 고유수용감각에 의존하는 정도에 영향을 미치게 되며, 폐 안을 통한 시각정보가 차단된 상태는 자세 흔들림이 증가하는 결과 를 가져와 고관절과 체간전략을 위한 근육의 활성도에 영향을 미친 다고 하였다.

본 연구에서 시각정보에 따라 앉기와 스쿼트 동작 모두 구간 1 에서 는 체간과 하지관절 각속도의 차이가 없었다. 구간 2에서 앉기는 시각 정보에 따라 체간과 하지관절 각속도 모두에서 유의한 차이가 나타 났으며, 스쿼트는 시각정보에 따라 골반과 고관절 각속도에서 유의한 차이가 나타났다. 이는 앉기와 스쿼트 동작의 구간 1 은 신체가 중력 과 함께 하향하면서 중력에 대한 원심성 수축이 발현되기 전으로 사 료되며, 신체의 감속이 나타나는 원심성 구간에서 안전하고 부드러 운 착석을 위해 시각정보와 자세조절에 따른 앉기와 스쿼트 동작의 차이가 나타난 것이라고 보여진다.

Donnelly 등13은 스쿼트 동작은 시선의 위치에 따라 운동학적 변인 이 달라진다고 하였으며, 시선이 아래를 향한 하방(donward)스쿼트 동작과 위를 향한 상방(upward)스쿼트 동작에서 고관절과 체간에 유 의한 차이가 나타났다고 하였다. 스쿼트 동작은 시선의 방향에 따라 요추부위에 영향을 준다고 하였으며 이는 본 연구에서 시각정보의 변화뿐 아니라 연구 대상자의 전. 상방에서 제공된 시각과제의 위치 또한 앉기와 스쿼트 동작에 영향을 미칠 수 있다는 것을 알 수 있다.

Kwon과 Lee ${ }^{24}$ 는 건강한 성인 24명을 대상으로 연속반응시간(Serial Reaction Time)과제를 위해 시각, 청각, 시청각 자극을 주었을 때 손가 락 운동의 반응 속도와 정확성이 개선되었다고 보고 한 바, 본 연구에 서 알아보고자 하였던 동작의 속도 변화와 일부 일치하는 것을 볼 수 있었다.

본 연구에서 일반적인 시각정보 상태에서 앉기와 스쿼트 동작을 비교 한 결과, 동작 구간 1 에서 슬관절, 족관절 각속도는 앉기가 스쿼 트 동작보다 유의하게 빠르게 나타났으며, 구간 2에서 체간과 하지관 절 모두의 각속도는 앉기가 스쿼트 동작보다 유의하게 빠르게 나타 났으며, 이는 앉기와 스쿼트 동작의 기본적인 형태 차이로 인한 결과 로 보여진다.

본 연구에서 시각과제에서 앉기와 스쿼트 동작을 비교 한 결과, 동 작 구간 1 에서 슬관절 각속도는 앉기가 스쿼트 동작보다 유의하게 빠 르게 나타났으며, 동작 구간 2에서 고관절과 슬관절, 족관절 각속도 는 앉기가 스쿼트 동작 보다 유의하게 빠르게 나타났으며, 이는 시각 과제 수행을 토대로 동작이 감속되는 정도의 차이로 설명 할 수 있다.

따라서 향후 지속적인 연구를 통하여 시각 정보 상태에 따라 앉기 와 스쿼트 동작을 동작의 주체인 근육의 활성도와 각운동의 차이 등 을 동시에 연구하여 운동 조절에서의 시각의 중요성이 인식될 수 있 기를 기대하며, 또한 시각이 운동조절에 미치는 영향이 서로 다른 동 작에 따라서 차이를 나타낼 수 있다는 것을 임상에서는 충분히 고려
하여야할 것으로 사료된다.

\section{REFERENCES}

1. Manckoundia P, Mourey F, Pfitzenmeyer P, et al. Comparison of motor strategies in sit-to-stand and back-to-sit motions between healthy and Alzheimer's disease elderly subjects. Neuroscience. 2006;137(2): 385-92.

2. Clément J, Hagemeister N, Aissaoui R, et al. Comparison of quasi-static and dynamic squats: A three-dimensional kinematic, kinetic and electromyographic study of the lower limbs. Gait \& posture, 2014;40(1):94-100.

3. Kerr KM, White JA, Barr DA, et al. Analysis of the sit-stand-sit movement cycle in normal subjects. Clinical Biomechanics. 1997;12(4):23645.

4. Schoenfeld BJ. Squatting kinematics and kinetics and their application to exercise performance. The Journal of Strength \& Conditioning Research. 2010;24(12):3497-506.

5. Escamilla RF. Knee biomechanics of the dynamic squat exercise. Medicine and science in sports and exercise. 2001;33(1):12741.

6. Hase K, Sako M, Ushiba J, et al. Motor strategies for initiating downward-oriented movements during standing in adults. Experimental brain research. 2004;158(1):18-27.

7. Shumway-Cook A \& Woollacott MA. Motor control: Translating research into clinical practice. 2012;161-94.

8. Horak FB. Clinial measurement of postural control in adults. Physical Therapy, 1987;676:1881-5.

9. Black FO, Wall III C, Rockette Jr HE, et al. Normal subject postural sway during the Romberg test. American journal of otolaryngology. 1982; 3(5):309-18.

10. Yardley L, Gardner M, Bronstein A, et al. Interference between postural control and mental task performance in patients with vestibular disorder and healthy controls. Journal of Neurology, Neurosurgery \& Psychiatry. 2001;71(1):48-52.

11. Andersson G, Hagman J, Talianzadeh R, et al. Dual-task study of cognitive and postural interference in patients with vestibular disorders. Otology \& neurotology. 2003;24(2):289-93.

12. Dubost V, Beauchet O, Manckoundia P, et al. Decreased trunk angular displacement during sitting down: An early feature of aging. Physical Therapy. 2005;85(5):404-12.

13. Donnelly DV, Berg WP, Fiske DM. The effect of the direction of gaze on the kinematics of the squat exercise. The Journal of Strength \& Conditioning Research. 2006;20(1):145-50.

14. Ferrante S, Pedrocchi A, Ferrigno G. Electromyographic analysis of standing up and sitting down. In 10th Annual Conference of the International FES Society. 2005;1-3.

15. Najafi B, Aminian K, Loew F, et al. Measurement of stand-sit and sitstand transitions using a miniature gyroscope and its application in fall risk evaluation in the elderly. Biomedical Engineering, IEEE Transactions. 2002;49(8):843-51.

17. Zijlstra A, Mancini M, Lindemann U, et al. Sit-stand and stand-sit transitions in older adults and patients with Parkinson's disease: event detection based on motion sensors versus force plates. J Neuroeng Rehabil, 2012;9:75.

18. Alves FSM, Oliveira FS, Junqueira CHBF, et al. Analysis of electromyo- 
graphic patterns during standard and declined squats. Brazilian Journal of Physical Therapy. 2009;13(2):164-72.

19. Carlton LG. Visual processing time and the control of movement. Advances in psychology. 1992;85:3-31.

20. Choi JS, Kang DW, Tack GR. Effects of walking speeds and cognitive task on gait variability. Korean Journal of Sports Biomechanics. 2008; 18(2):49-58.

21. Potter CN, \& Silverman LN. Characteristics of vestibular function and static balance skills in deaf children. Physical therapy. 1984;64(7):1071-5.

22. Dionisio VC, Almeida GL, Duarte M, et al. Kinematic, kinetic and EMG patterns during downward squatting. Journal of Electromyography and
Kinesiology. 2008;18(1):134-43.

22. Salem GJ, \& Powers CM. Patellofemoral joint kinetics during squatting in collegiate women athletes. Clinical Biomechanics. 2001;16(5):424-30.

23. Won MH, Kim MC, Kim SJ, et al. The effect of visual information provision on the changes of electromyogram activity in trunk and lower leg muscles during dynamic balance control. The Korean Journal of Sports Medicine. 2014;32(1):44-54.

24. Kwon YH, Lee MH. Comparison of motor skill acquisition according to types of sensory stimuli cue in serial reaction time task. J Kor Phy Ther. 2014;26(3):191-5. 